\title{
RAIN EFFECT ON KU-BAND SATELLITE SYSTEM
}

\author{
Jalal J. Hamad Ameen ${ }^{1}$ \\ ${ }^{1}$ Department of Electrical Engineering, Salahaddin University, Erbil City , Iraq
}

\begin{abstract}
Satellite system has many frequency bands, Ku-band is the most used bands in satellite services like DVB, $D A B$, Internet, the ionosphere influences specially, rain has the direct effect on the satellite signal and causes decrease in the received signal, this paper is an attempt to study, calculation of rain effect in Iraqi Kurdistan region, some results presented and finally, some solutions and recommendations presented to reduce the rain effect hope be useful for any satellite system users in any locations to minimize this effect, improvement and increase in the received signal.
\end{abstract}

\section{KEYWORDS}

$K u$-Band satellite system, rain effect, rain attenuation calculation

\section{INTRODUCTION}

Satellite communication system like other systems has some impairments for example, the transmitting and receiving equipment, polarization mismatch losses, di-pointing losses and freespace losses, the first three impairments can be improved and overcome their effects is not impossible, but the last one needs some technical and special methods to reduce not to overcome but to reduce its effects, free space losses in clear sky exists and affects the signal, and this loss increases in case of rain, snow, heavy clouds, specially, the regions with heavy rain suffering from the disconnecting the received signal during rains, this paper is an attempt how to calculate the free space losses and then the received signal during rain and clear sky, comparing the two results to see the amount of losses, then how to compensate these losses, then, finally, giving the signal continuity without interruption of the received signal.

After the introduction section, there will be a brief discussion about the satellite system, the impairments, then, the free space losses in more details, calculation of the rain effect, as an example in Iraqi Kurdistan region for the four seasons, the methods to compensate these losses, results and some conclusions.

\section{KU-BAND DifFICULTIES}

When frequencies higher than $10 \mathrm{GHz}$ are transmitted and received in a heavy rain fall area, a noticeable degradation occurs, due to the problems caused by and proportional to the amount of rain fall (commonly known as known as "rain fade").

This problem can be combated, however, by deploying an appropriate link budget strategy when designing the satellite network and allocating a higher power consumption to overcome rain fade loss. In terms of end-viewer TV reception, it takes heavy rainfalls in excess of $100 \mathrm{~mm}$ per hour to have a noticeable effect, Figure 1 is for the rain effect in satellite system in up-link and Figure 2 for down -link respectively. 
A similar phenomena called "snow fade" (when snow accumulation significantly alters the dish's focal point) can also occur during Winter Season.

Also, the $\mathrm{Ku}$ band satellites typically require considerably more power to transmit than the $\mathrm{C}$ band satellites. However, both $\mathrm{Ku}$ and $\mathrm{Ka}$ band satellite dishes are smaller (varying in size from $2^{\prime}$ to $5^{\prime}$ in diameter.) but, larger dish will causes in increase for the received signal and better quality of the system.

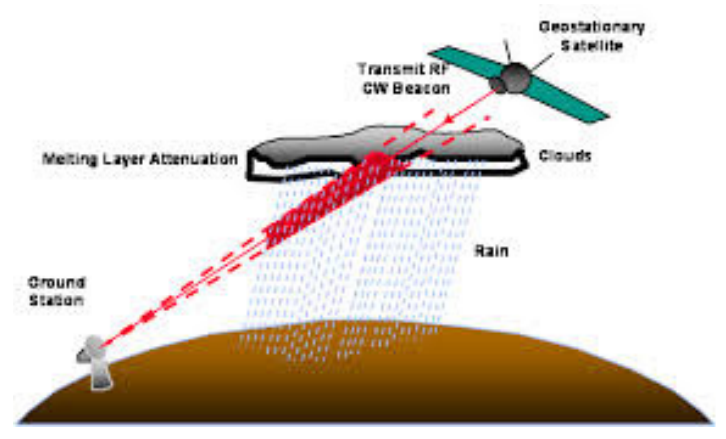

Figure. 1 Rain Effect on Satellite System (up-link)

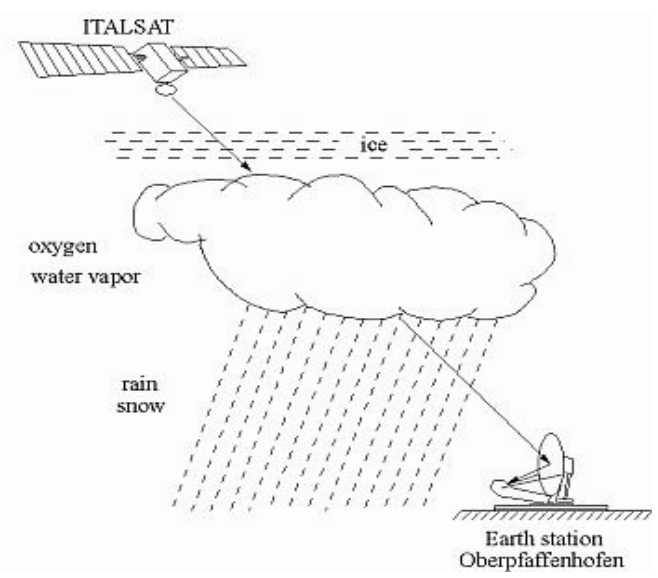

Figure. 2 Rain Effect on Satellite System (down-link)

Advantages of Ku-band compared with C-band, this band is not similarly restricted in power to avoid interference with terrestrial microwave systems, and the power of its uplinks and downlinks can be increased. This higher power also translates into smaller receiving dishes and points out a generalization between a satellite's transmission and a dish's size. As the power increases, the dish's size can decrease. This is because the purpose of the dish element of the antenna is to collect the incident waves over an area and focus them all onto the antenna's actual receiving element, mounted in front of the dish (and pointed back towards its face); if the waves are more intense, fewer of them need to be collected to achieve the same intensity at the receiving element.

Also, as frequencies increase, parabolic reflectors become more efficient at focusing them. The focusing is equivalent given the size of the reflector is the same with respect to the wavelength. At $12 \mathrm{GHz}$ a 1-meter dish is capable of focusing on one satellite while sufficiently rejecting the signal from another satellite only 2 degrees away. This is important because satellites in FSS (Fixed Satellite Service) service (11.7-12.2 GHz in the U.S.) are only 2 degrees apart. At $4 \mathrm{GHz}$ (C-band) a 3-meter dish is required to achieve this narrow of a focus beam. Note the inverse 
linear correlation between dish size and frequency. For Ku satellites in DBS (Direct Broadcast Satellite) service (12.2-12.7 GHz in the U.S.) dishes much smaller than 1-meter can be used because those satellites are spaced 9 degrees apart. As power levels on both $\mathrm{C}$ and $\mathrm{Ku}$ band satellites have increased over the years, dish beam-width has become much more critical than gain. The $K_{u}$ band also offers a user more flexibility. A smaller dish size and a $K_{u}$ band system's freedom from terrestrial operations simplifies finding a suitable dish site. For the end users $K_{u}$ band is generally cheaper and enables smaller antennas (both because of the higher frequency and a more focused beam). $K_{u}$ band is also less vulnerable to rain fade than the $K_{a}$ band frequency spectrum. The satellite operator's Earth Station antenna does require more accurate position control when operating at $\mathrm{K}_{\mathrm{u}}$ band due to its much narrower focus beam compared to $\mathrm{C}$ band for a dish of a given size. Position feedback accuracies are higher and the antenna may require a closed loop control system to maintain position under wind loading of the dish surface.

However, as a disadvantage of $\mathrm{K}_{\mathrm{u}}$ band system especially at frequencies higher than $10 \mathrm{GHz}$ in heavy rainfall areas, a noticeable degradation occurs, due to the problems caused by and proportional to the amount of rainfall (commonly known as "rain fade"). This problem can be mitigated, however, by deploying an appropriate link budget strategy when designing the satellite network, and allocating a higher power consumption to compensate rain fade loss. The $\mathrm{K}_{\mathrm{u}}$ band is not only used for television transmission, which some sources imply, but also very much for digital data transmission via satellites, and for voice/audio transmissions.

The higher frequency spectrum of the $\mathrm{K}_{\mathrm{u}}$ band is particularly susceptible to signal degradation, considerably more so than C-band satellite frequency spectrum. A similar phenomenon, called "snow fade" (where snow or ice accumulation significantly alters the focal point of a dish) can also occur during winter precipitation. Also, the $\mathrm{K}_{\mathrm{u}}$ band satellites typically require considerably more power to transmit than the C-band satellites. Under both "rain fade" and "snow fade" conditions, $\mathrm{K}_{\mathrm{a}}$ and $\mathrm{K}_{\mathrm{u}}$ band losses can be marginally reduced using super-hydrophobic Lotus effect coatings.

\section{Influence of the atmosphere}

On both the up- and downlinks, the carrier passes through the atmosphere. Recall that the ranger of frequencies concerned is from 1 to $30 \mathrm{GHz}$. From the point of view of wave propagation at these frequencies, only two regions of the atmosphere have an influence the troposphere and the ionosphere. The troposphere extends practically from the ground to an altitude of $15 \mathrm{~km}$. the ionosphere is situated between around 70 and $1000 \mathrm{~km}$, the regions where their influence is maximum are in the vicinity of the ground for the troposphere and an altitude of the order of 400 $\mathrm{km}$ for the ionosphere. The influence of the atmosphere has been mentioned previously in order to introduce the losses LA due to atmosphere attenuation and in connection with antenna noise temperature. Figure 3 is the relation between the free space losses versus frequency for clear sky. However, other phenomena can occur. The predominant effects are those caused by absorption and depolarization due to tropospheric precipitation (rain and snow), dry snow has little effect. Although wet snowfalls can cause greater attenuation than the equivalent rainfall rate, this situation is rate and little effect on attenuation statistics. Effects are particularly significant for frequencies greater than $10 \mathrm{GHz}$. The occurrence of rain is defined by the percentage of time during which a given rainfall rate is exceeded, low rainfall rates with negligible effects correspond to high percentage of time (typically 20\%); these are described as clear sky conditions. High rainfall rate with significant effects, correspond to small percentage of time (typically $0.01 \%$ ); these are described as rain conditions. These effects can degrade the quality of the link below an acceptable threshold. The availability of a link is thus directly related to the rainfall rate time statistics. In view of their importance, the effects of precipitation are presented first. There are several of main problems of propagation using Ku-band satellite links : 
Electrical and Electronics Engineering: An International Journal (ELELIJ) Vol 4, No 2, May 2015

Rain attenuation - The attenuation of the signal due rain is the most remarkable propagation effect of the signal in the Ku-band frequency, this kind of lost occur due to the previous thing, can be greater than $15 \mathrm{~dB}$ for a small amount of time.

Gaseous absorption - The loss of approximately $1 \mathrm{~dB}$ happens due to the steam absorption of oxygen and water.

Cloud attenuation - The clouds that are in the propagation trajectory can attenuate the signal at the frequency of the Ku-band, the amount of attenuation that happens is of approximately of $1 \mathrm{~dB}$ or more.

Scintillation - This term is indicative of fast fluctuations in the amplitude of the signal, this is caused by the changes that happen by the variation of the time in the refractive index of the atmosphere, it can also be caused by rainstorms.

Depolarization - The transference of energy from a state of polarization in its orthogonal state can be caused by the atmosphere, mainly in clouds and the rain.

Atmospheric noise - The atmosphere has a temperature equivalent of a black body, in the frequency of Ku-band, this temperature varies from about $10 \mathrm{~K}$ to close to the temperature of the ambient.

Wet antenna - The condensation in the antennas causes additional loss of the signal In this paper, we just concern about the concurrent $\mathrm{Ku}$-band rain attenuation and tropospheric scintillation issues.

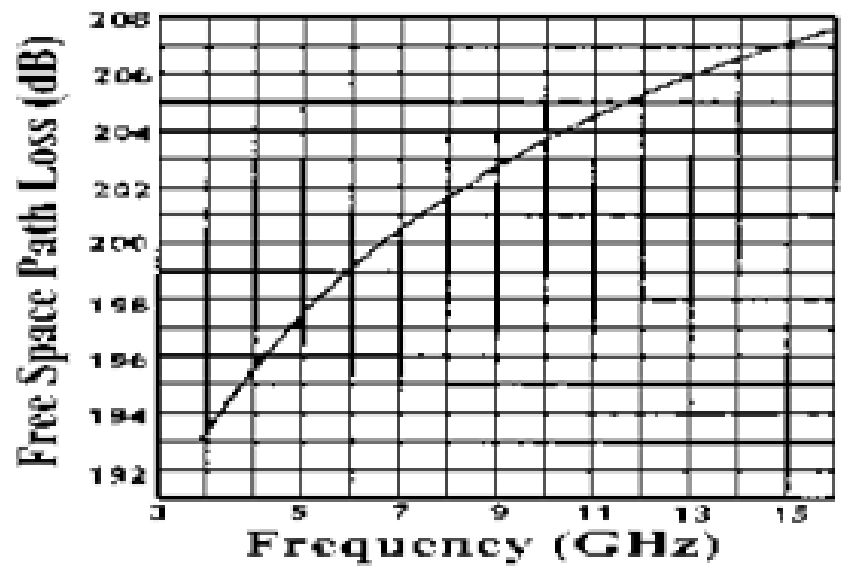

Figure. 3 Free-space path loss vs. frequency in clear sky[1]

\section{Calculation of rain attenuation}

Rain effect attenuation can be calculated in several steps commonly for any location in the world, the data will be different from location to other depending the weather, in this paper, the calculation is for Iraqi Kurdistan region for the five cities : Erbil, Sulaimanyia, Duhok, Kirkuk and Halabja, where has four seasons Winter, Spring, Summer and Autumn. 
Electrical and Electronics Engineering: An International Journal (ELELIJ) Vol 4, No 2, May 2015

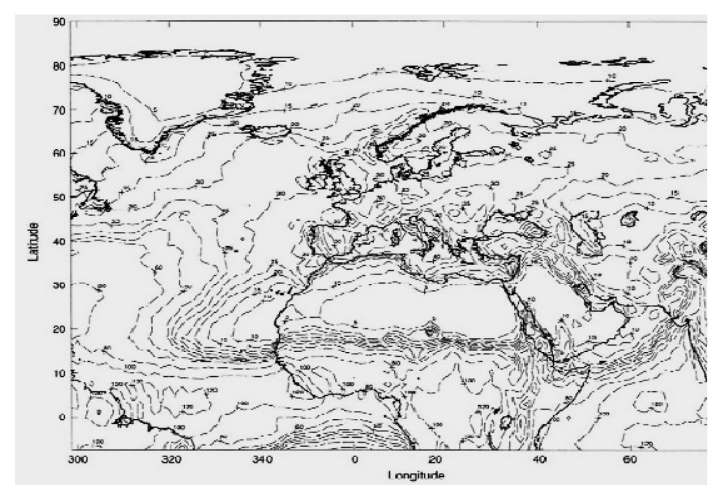

Figure. 4 Longitude and Latitude for overall earth zones[1]

Rain starts from October and ends from April or sometimes on May, temperature decreases and rain fall will be maximum after November until April, the value of attenuation due to rain $A_{\text {rain }}$ is given the product of specific attenuation $y_{R}(\mathrm{~dB} / \mathrm{km})$ and the effective path length of the wave in the $L_{e}(\mathrm{~km})$, that is the overall rain attenuation is given by :

$A_{\text {rain }}=y_{R} L_{e}$

The value of $y_{R}$ depends on the frequency and intensity $\mathrm{R}_{\mathrm{p}}(\mathrm{mm} / \mathrm{h})$ of the rain. The result is a value of attenuation which is exceeded during the percentage of time $\mathrm{p}$. The calculation of $A_{\text {rain }}$ done in several steps according to the location mentioned above in this paper.

Kurdistan region located in region $\mathrm{K}$ as shown in Figure 5, this means that the rain rate will be between $2-100 \mathrm{~mm} / \mathrm{Hr}$ depending on the rain rates $1 \%-0.001 \%$ according to the Table I for the rain rate chart CCIR Rain Zones.

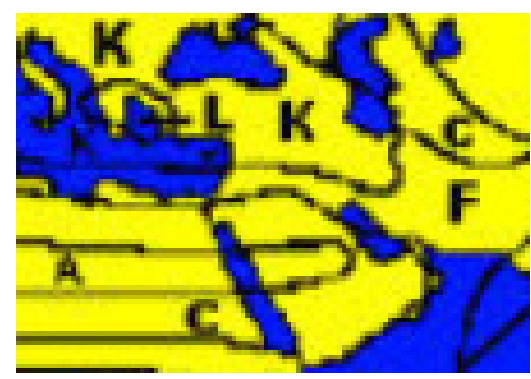

Figure. 5 Rain rate region sections 
Electrical and Electronics Engineering: An International Journal (ELELIJ) Vol 4, No 2, May 2015

Table 1. CCIR rain zone rain rats in $\mathrm{mm} / \mathrm{Hr}$ for different zones

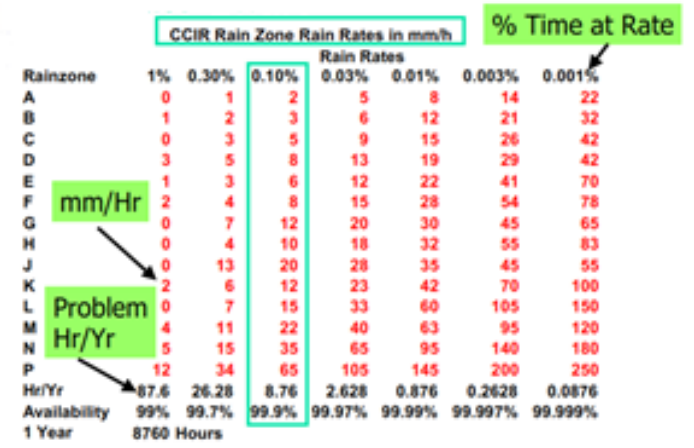

Figure 6, Kurdistan region average $0^{\circ} C$ isotherm height above mean sea level $h_{o}$ is $3 \mathrm{~km}$.

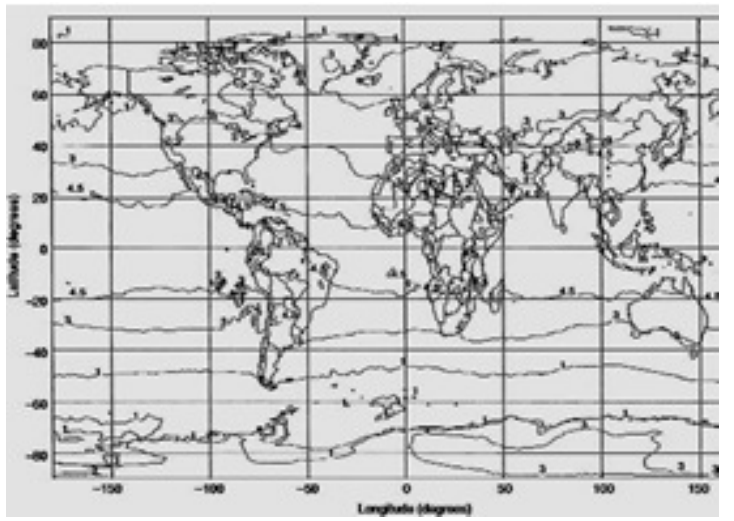

Figure. 6 Yearly average $0^{\circ} \mathrm{C}$ isotherm height above mean sea level(km)[1]

The steps to calculate the attenuation caused by rain given in the flow chart below, it starts by calculation of mean rain height above mean sea level and ends by calculating specific attenuation $y_{R}(\mathrm{~dB} / \mathrm{km})$ and the effective path length of the wave in the $L_{e}(\mathrm{~km})$, finally, the overall rain attenuation $A_{\text {rain }}$. 
Electrical and Electronics Engineering: An International Journal (ELELIJ) Vol 4, No 2, May 2015

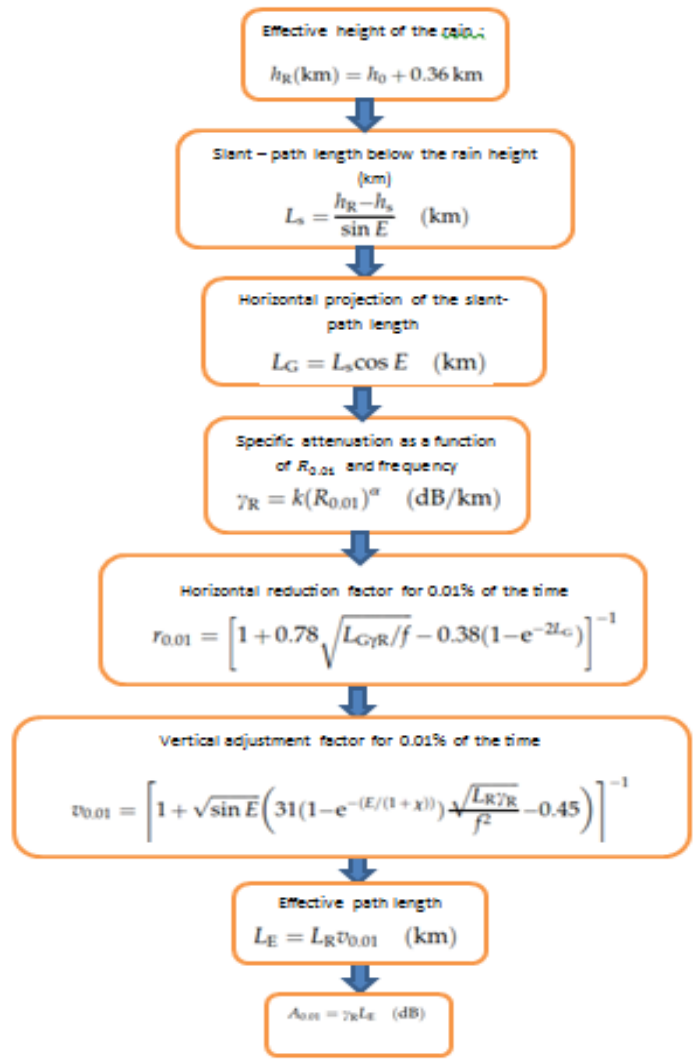

Where,

\section{$k_{0}$ is the mean $0 \mathrm{C}$ isolkerm height above moan sea letel}

where $h_{2}(\mathrm{~km})$ is the earth station height above mean sea level and $E$ is the satellite elevation angle. This is valid for $E \geq 5$,

$k=\left|k_{H}+k_{V}+\left(k_{H}-k_{V}\right) \cos ^{2} E \cos 2 t\right| / 2$

$\alpha=\left|k_{H} \alpha_{H}+k_{V} \alpha_{V}+\left(k_{H} \alpha_{H}-k_{V} \alpha_{V}\right) \cos ^{2} E \cos 2 \pi\right| / 2 \mathrm{k}$

$E$ is the elevation angle and $t$ is the polarisation tilt angle relative to the horizontal

$L_{\mathrm{E}}$ in $\mathrm{km}, \gamma_{\mathrm{R}}$ in $\mathrm{dB} / \mathrm{km}, f$ in $\mathrm{GHz}$

$$
\begin{aligned}
& \xi=\tan ^{-1}\left(\frac{h_{\mathrm{R}}-h_{s}}{L_{G} r_{001}}\right) \quad \text { (degrees) } \\
& L_{\mathrm{k}}(\mathrm{km})= \begin{cases}L_{\mathrm{G}} r_{00 \mathrm{O}} / \cos E & \text { for } \zeta>E \\
\left(h_{\mathrm{K}}-h_{\mathrm{s}}\right) / \sin E & \text { otherwise }\end{cases} \\
& x=\left\{\begin{array}{lr}
36-\mid \text { latitude } \mid \text { if } \mid \text { latitude } \mid<36 \\
0 & \text { otherwise }
\end{array}\right.
\end{aligned}
$$


Electrical and Electronics Engineering: An International Journal (ELELIJ) Vol 4, No 2, May 2015

\section{Results}

In this paper, the attenuation causes by rain calculated for the five cities in Iraqi Kurdistan region, the longitude and latitude are given in Table 2, also, the calculated parameters needed are given in the Table for the Ku-band in the frequency range from $10 \mathrm{GHz}$ to $12 \mathrm{GHz}$ ( $10 \mathrm{GHz} \leq \mathrm{f} \leq 12 \mathrm{GHz}$ ) :

$0.0101 \leq k_{H} \leq 0.0188,0.00887 \leq k_{v} \leq 0.0168$

$1.276 \leq \propto_{H} \leq 1.217,1.264 \leq \propto_{V} \leq 1.200$

Height above sea level for Erbil, Sulaimanyiah, Kirkuk, Duhok, and Halabjah $\left(\mathrm{h}_{\mathrm{s}}\right)$ are $0.428 \mathrm{~km}$, $0.807 \mathrm{~km}, 0.308 \mathrm{~km}, 0.553 \mathrm{~km}$ and $0.718 \mathrm{~km}$ respectively, elevation angles $(\mathrm{E})=90-$ Zenith angle

where, Zenith angle is the angle between the sun and the vertical.

Therefore from the longitude and latitude locations for the five cities, the zenith angles are $30.47^{0}, 31.11^{0}, 31.19^{0}, 29.77^{0}, 31.48^{0}$, as a result, the elevations (E) will be respectively : $59.53^{0}, 58.89^{0}, 58.81^{0}, 60.23^{0}$ and $58.52^{0}$.

Table 2. Locations characteristics and results for Kurdistan region

\begin{tabular}{|c|c|c|c|c|c|c|}
\hline Location & Lat. & Long. & $\begin{array}{l}\text { RainRateato. } \\
01 \%(\mathrm{~mm} / \mathrm{hr})\end{array}$ & $E^{o}$ & $\mathbf{L}_{\mathrm{s}}(\mathbf{k m})$ & $\mathbf{L}_{\mathrm{G}}(\mathbf{k m})$ \\
\hline Erbil & 36.27 & 44.08 & $43 \mathrm{~mm} / \mathrm{hr}$ & 59.53 & 3.41 & 1.72 \\
\hline Sulaimanyia & 35.63 & 45.44 & $40 \mathrm{~mm} / \mathrm{hr}$ & 58.89 & 2.98 & 1.54 \\
\hline Duhok & 36.85 & 43.13 & $41 \mathrm{~mm} / \mathrm{hr}$ & 58.81 & 3.56 & 1.87 \\
\hline Kirkuk & 35.63 & 44.32 & $37 \mathrm{~mm} / \mathrm{hr}$ & 60.23 & 3.23 & 1.60 \\
\hline Halabjah & 35.23 & 45.93 & $39 \mathrm{~mm} / \mathrm{hr}$ & 58.52 & 3.09 & 1.61 \\
\hline
\end{tabular}

For $\mathrm{Ku}$-band, the specific attenuation is about $5 \mathrm{~dB}$ for $50 \mathrm{~mm} / \mathrm{hr}$ as average, also, $\mathrm{k}$ and $\alpha$ for the band which has the following calculated parameters Will be :

$0.0101 \leq k_{H} \leq 0.0188,0.00887 \leq k_{v} \leq 0.0168$

$1.276 \leq \propto_{H} \leq 1.217,1.264 \leq \propto_{V} \leq 1.200$

Where, $\mathrm{f}=10 \mathrm{GHz}, \mathrm{k}=0.0096, \alpha=0.0123$, therefore, $y_{R}=0.0097 \mathrm{~dB} / \mathrm{km}$ for vertical polarization, $\mathrm{k}=0.0189, \alpha=0.0238$, therefore, $y_{R}=0.0194 \mathrm{~dB} / \mathrm{km}$ for horizontal polarization.

Where, $\mathrm{f}=12 \mathrm{GHz}, \mathrm{k}=0.0181, \alpha=0.0219$, therefore, $y_{R}=0.0187 \mathrm{~dB} / \mathrm{km}$ for vertical polarization, $\mathrm{k}=0.0356, \alpha=0.0429$, therefore, $y_{R}=0.0381 \mathrm{~dB} / \mathrm{km}$ for horizontal polarization, as a result, for the range of ku-band : $10 \mathrm{GHz} \leq \mathrm{f} \leq 12 \mathrm{GHz}$

$0.0097 \leq y_{R} \leq 0.0187$ for vertical polarization and $0.0194 \leq y_{R} \leq 0.0381$ for horizontal polarization.

And the effective path length $L_{e}$ is approximately the slant path length $\mathrm{L}_{\mathrm{s}}$ because $\mathrm{E}>\zeta$, agiven in Table $3: 3.41,2.98,3.56,3.23$ and 3.09 for the five locations, as a result the rain attenuation $A_{\text {rain }}$ which is the multiplication of $L_{e}$ and $y_{R}$ given in equation (1) will be as given in Table IV 
Electrical and Electronics Engineering: An International Journal (ELELIJ) Vol 4, No 2, May 2015

Table 3. Predicted rain attenuation for the five locations

\begin{tabular}{|l|l|l|}
\hline \multirow{2}{*}{ Location } & $\boldsymbol{A}_{\text {rain }}(\mathbf{d B})$ & Horizontal Pol. \\
\cline { 2 - 3 } & Vertical Pol. & $0.066-0.129$ \\
\hline Erbil & $0.033-0.063$ & $0.057-0.113$ \\
\hline Sulaimanyiah & $0.028-0.055$ & $0.069-0.135$ \\
\hline Kirkuk & $0.034-0.066$ & $0.062-0.123$ \\
\hline Duhok & $0.031-0.060$ & $0.059-0.117$ \\
\hline Halabjah & $0.029-0.057$ & \\
\hline
\end{tabular}

Figures 7-11 are the path losses comparison in clear sky and rain situation for horizontal and vertical polarization signals predicted for the five cities in Iraqi Kurdistan region Erbil, Sulaimanyiah, Kirkuk, Duhok and Halabjah respectively.

It is shown that horizontal polarized signals affected by the rain and causes higher rain attenuation and then higher decrease in the received signal than the vertical polarized signals.

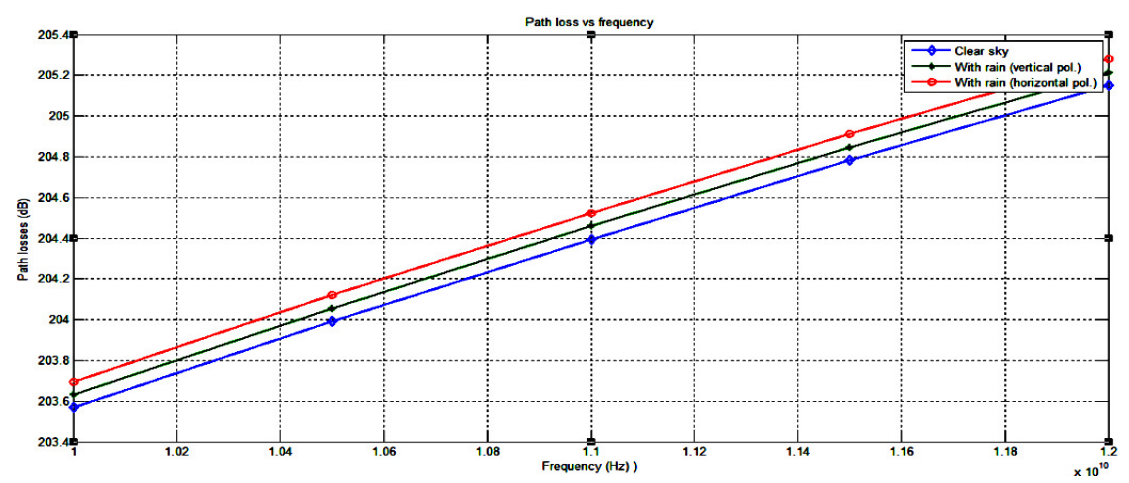

Figure. 7 Path loss vs. frequency for Erbil city

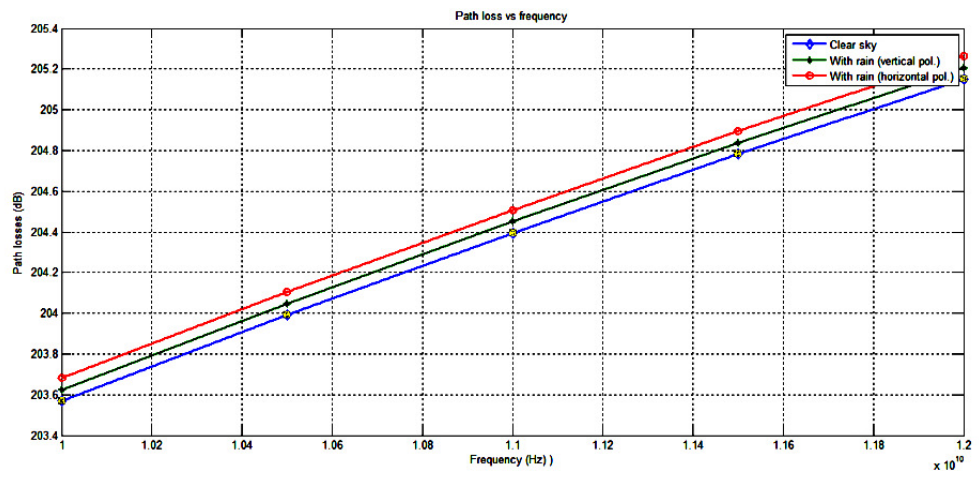

Figure. 8 Path loss vs. frequency for Sulaimanyiah city 
Electrical and Electronics Engineering: An International Journal (ELELIJ) Vol 4, No 2, May 2015

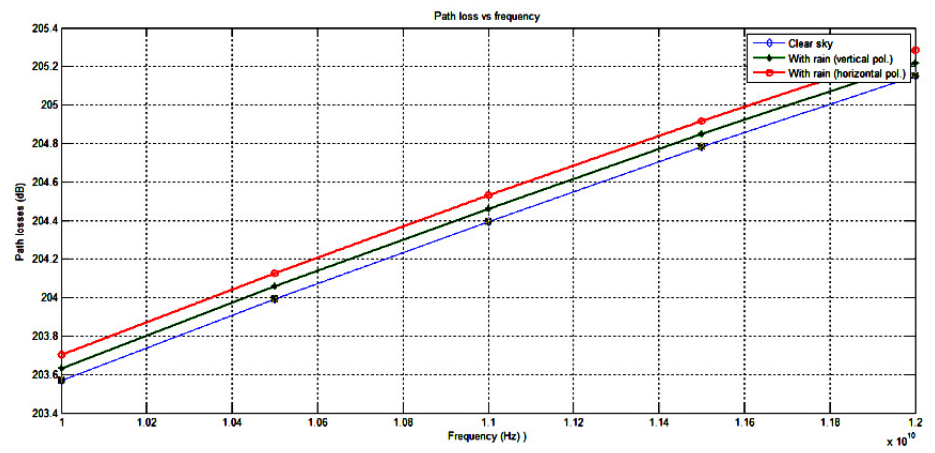

Figure. 9 Path loss vs. frequency for Kirkuk city

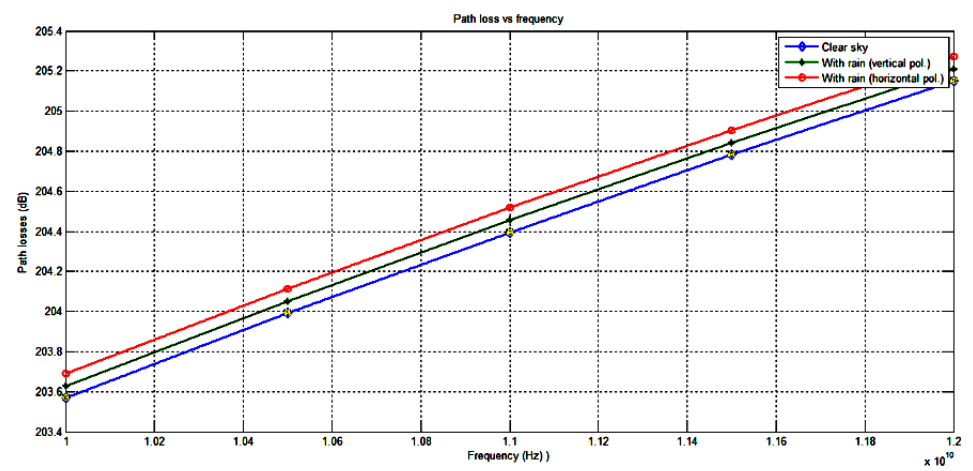

Figure. 10 Path loss vs. frequency for Duhok city

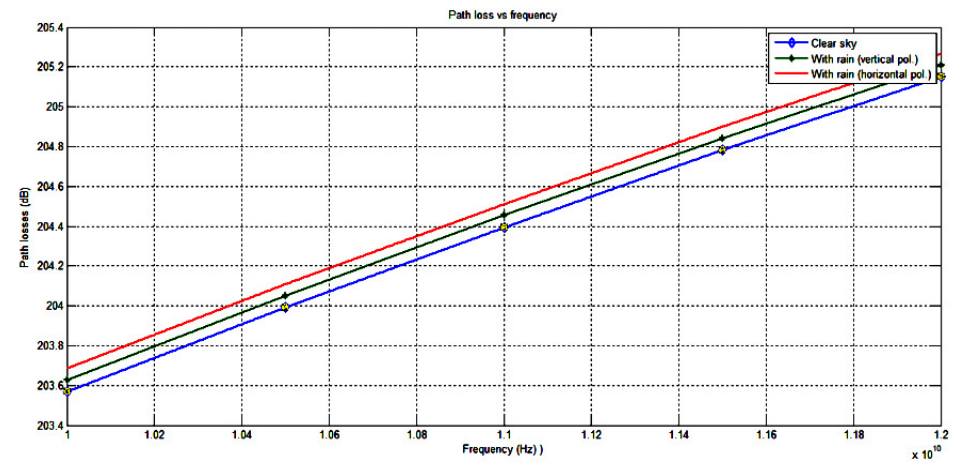

Figure. 11 Path loss vs. frequency for Halabjah city

After the calculations and shown results, it is clear that the rain has the effect on the received signal and causes decrease in the received signal, as a technical recommendations for the user how to decrease this effect, there will be for the two sides up-link side and down-link side, for the up-link side :

1. Greater antenna reflector diameter with higher gain.

2. Tracking the weather situations for the four seasons specially the months rain starts as mentioned in section IV in this paper to increase the transmitting power for heavy rain in order to compensate the loss causes by rain attenuation. 
Electrical and Electronics Engineering: An International Journal (ELELIJ) Vol 4, No 2, May 2015

3. Because for the vertical polarized signals, the rain effect is less than that for horizontal, vertical polarization is preferred.

For the down-link side, using antenna reflectors with greater diameter and higher gain, also the distance between the LNB and the reflector preferred that must be prevented from the rain.

\section{Conclusions}

Satellite signal affected by the atmosphere situations, like snow, rain, and clouds, in this paper, the attenuation causes with rain which increased the path loss has been predicted for Iraqi Kurdistan region main cities Erbil, Sulaimanyiah, Kirkuk, Duhok and Halabjah, it is shown from the results that the horizontal polarized signals affected greater than that with vertical polarized, also, the approximately predicted amount of attenuation causes by rain presented, finally, some useful recommendations to minimize this attenuation and then improve the received signal has been presented.

\section{REFERENCES}

[1] GerardMaral and Michel Bousquet, "Satellite Communications Systems, systems, Techniques, and Technologies", Wiley, book, 5th edition, John Wiley and Sons Ltd, 2009.

[2] Shkelzen CAKAJ, “Rain Attenuation Impact on Performance of Satellite Ground Stations for Low Orbiting (LEO) Satellites in Europe" , International Journal on Communications, Network and System Sciences, 2009,6, pages 480-485.

[3] arat Kumar K, VijayaBhaskara Rao S, and Narayana Rao, “ Prediction of Ku Band Rain Attenuation Using Experimental Data and Simulations for Hassan, India:, International Journal of Computer Science and Network Security, Bol. 8, No. 4, April 2008.

[4] S. J. Malinga, P. A. Owolawi, and T. J. O. Afullo, "Estimation of Rain Attenuation at C, Ka, Ku and V Bands for Satellite Links in South Africa” PIERS Proceedings, Taipei, March 25-28, 2013.

[5] RenukaNalinggan, Widad Ismail, and J. S. Mandeep, " Rain-induced attenuation for Ku-band satellite communications in the west coast of Peninsular Malaysia, Penang", Ann. Telecomm. (2012), Institute Minues-Telecom and Springer-Verlag 2012, 27 April 2012.

[6] T.SivaPriya* andT.Nizhanthi, "A Study on the effects of Rain Attenuation for an X-Band Satellite System over Malaysia”, ProgressInElectromagneticsResearchB,Vol.45, 37-56,2012.

[7 M.Sridhar1,K.PadmaRaju2,andCh.SrinivasaRao, "Estimation of Rain Attenuation based on ITU-R Model in Guntur, (A.P), India", ACEEEInt.J.onCommunications,Vol.03,No.02,Nov2012, pages 6-10.

[8] J. S. Ojoand M. O. Ajewole, "Rain Rate and Rain Attenuation Prediction for Satellite Communication in $\mathrm{Ku}$ and Ka Bands over Negeria", Progress In Electromagnetics Research B, Vol. 5, 207-223, 2008, pages 207-223

\section{AUTHOR BIOGRAPHY :}

Jalal Jamal HamadAmeen : ReceivedBachlore of Science (BSc) in Electronics and Communications Engineering,University of Salahaddin, Erbil ,Iraq, July 1991, Master of Science (MSc) in Communications Engineering, University Of Technology, Baghdad, Iraq, November 2004, The PhD in Mobile and Wireless Communications October, 2012, UniversitiSains Malaysia (USM). From 1992 until 2002 he was lecturer in Communications lab. From 2004 until 2008 was Lecturer of communications engineering ( digital and electronic communications) in Electrical Engineering department, University of Salahaddin, Erbil, Iraq. And now a lectures as Dr. in Electrical Engineering department, College of Engineering, Salahaddin University, Erbil, Iraq. His research interests include Wireless Systems, Mobile systems, CDMA systems, Fiber optic systems and satellite system. His e-mail is : Jalal3120002000@yahoo.com or jalaljamal133@gmail.com 